\title{
PELATIHAN STRATEGI-STRATEGI DALAM MEMECAHKAN MASALAH MATEMATIKA UNTUK GURU SMP/MTS
}

\author{
Sri Indriati Hasanah ${ }^{1}$, Hasan Basri ${ }^{2}$, Darus Salam ${ }^{3}$ \\ FKIP, Universitas Madura \\ ${ }^{1}$ Email : indriati_math@unira.ac.id
}

\begin{abstract}
Abstrak: Berdasarkan survey yang dilakukan terhadap guru-guru yang ada di daerah Pademawu, masih banyak guru-guru yang kurang mampu dalam mengerjakan soal-soal pemecahan masalah atau Problem Solving. Hal ini didasarkan pada hasil observasi yang dilakukan oleh penulis terhadap dokumen soal ujian harian yang digunakan oleh beberapa guru Smp/Mts di Pademawu, berdasarkan wawancara singkat diperoleh informasi bahwa salah satu alasan guru menggunakan soal-soal rutin adalah kurangnya pengetahuan guru terhadap strategi atau cara penyelesaiannya. Oleh sebab itu diperlukan pelatihan yang dilaksanakan oleh pihak lain (Perguruan Tinggi ) bagi guru mata pelajaran matematika SMP/Mts dalam memahami dan menerapkan strategi-strategi dalam memecahkan masalah matematika. Dengan bantuan dana hibah pengabdian dari LP3M Universitas Madura (UNIRA), maka pada tanggal 22-23 Februari 2016 diadakan "Pelatihan Strategi-Strategi Dalam Memecahkan Masalah Matematika Untuk Guru Smp/Mts di Pademawu”.Adapun strategi-strategi pemecahan masalah yang disampaikan dalam pelatihan ini adalah strategi menemukan pola, strategi semua kemungkinan secara sistematik, strategi tebak dan periksa, di hari pertama pada tanggal 22 Februari 2016. Staregi menyelesaikan masalah yang mirip atau masalah yang lebih mudah, strategi penalaran, strategi menyederhanakan permasalahan di hari kedua pada tanggal 23 Februari 2016. Metode yang digunakan dalam pelatihan ini terdiri dari tiga tahap yaitu : tahap pertama pemberian pre test, tahap kedua pemaparan strategi-strategi dalam pemecahan masalah dan tahap yang terakhir adalah pemberian post test. Berdasarkan hasil pre test dan post test dari peserta pelatihan dapat disimpulkan bahwa ada peningkatan kemampuan peserta pelatihan dalam menyelesaikan soal-soal pemecahan masalah. Dengan demikian pemberian pelatihan strategi-strategi pemecahan masalah dapat menjadi salah satu alternatif untuk meningkatkan kemampuan guru dalam pemecahan masalah.
\end{abstract}

Kata Kunci : Strategi-strategi, pemecahan masalah.

\section{PENDAHULUAN}

Pamekasan sebagai
pendidikan tentunya telah banyak
melahirkan siswa-siswa yang berprestasi
seperti juara lomba olimpiade nasional
maupun olimpiade tingkat internasional,
bahkan ada seorang siswa yang berhasil
memperoleh medali emas pada ajang
olimpiade internasional atas nama
Mohammad Shohibul Maromi yang
berhasil meraih medali emas pada ajang
International Physic Olympiad (IPhO) atau
Olimpiade Fisika tingkat dunia ke-41 yang
diselenggarakan di Zegreb, Kroasia, 17-25

Juli 2010. Namun demikian jika melihat latar belakang dan asal sekolah siswasiswa yang berprestasi tersebut, ternyata banyak dari mereka yang berasal dari sekolah yang ada di daerah kota. Berdasarkan data yang diperoleh untuk lomba Olimpiade Sains Nasional (OSN) matematika tingkat kabupaten pada tahun 2014 dan 2015 tidak ada 1 siswapun yang berasal dari kecamatan Pademawu yang berhasil menjadi wakil kabupaten Pamekasan di tingkat Provinsi, hal ini tentunya mengindikasikan ketidakmerataan kemampuan siswa. Guru 
yang ada di kecamatan Pademawu tentunya berpengaruh besar dalam meningkatkan kemampuan siswa-siswanya dalam memecahkan masalah matematika sehingga tidak terjadi kesenjangan antara siswa yang berada di kota dengan di pedesaan.

Soal-soal yang diberikan pada soal OSN baik tingkat Kabupaten, Provinsi maupun Nasional merupakan soal-soal problem solving atau pemecahan masalah, soal-soal ini tentunya agak berbeda dengan soal-soal yang ada di buku-buku teks pelajaran yang dimiliki oleh guru dan siswa. Pemecahan masalah adalah upaya yang dilakukan untuk memperoleh solusi masalah yang tidak dengan segera dapat dicapai dengan menggunakan pengetahuan, pemahaman dan keterampilan yang dimiliki (Irawati \& Hasanah, 2016). Adapun tahapan dalam memecahkan masalah menurut Polya (1973) adalah memahami masalah, merencanakan pemecahan, melaksanakan rencana, dan melihat kembali. Kemampuan seorang guru harus terus ditingkatkan seiring dengan perkembangan zaman dan perubahan kurikulum, namun pada kenyataannya masih banyak guru yang kurang siap dengan perubahan kurikulum yang diberlakukan oleh pemerintah yaitu kurikulum 2013. Berdasarkan survey dan hasil observasi yang dilakukan oleh penulis terhadap dokumen soal ujian harian yang digunakan oleh beberapa guru Smp/Mts di Pademawu, dari hasil wawancara singkat diperoleh informasi bahwa salah satu alasan guru menggunakan soal-soal rutin adalah kurangnya pengetahuan guru terhadap strategi atau cara penyelesaian soal-soal pemecahan masalah.

Beberapa strategi-strategi yang dapat digunakan dalam memecahkan masalah matematika menurut Suherman (2003) yaitu Strategi Act It Out, Membuat gambar atau diagram, Menemukan Pola, Membuat tabel, Memperhatikan semua kemungkinan secara sistematik, Tebak dan periksa (Guess and Check), Strategi kerja mundur, Menentukan apa yang diketahui, apa yang ditanyakan, dan informasi yang diperlukan, Menggunakan kalimat terbuka, Menyelesaikan masalah yang mirip atau masalah yang lebih mudah, Mengubah sudut pandang. Masih banyak guru-guru yang kurang mampu dalam mengerjakan soal-soal pemecahan masalah atau Problem Solving, oleh sebab itu diperlukan pelatihan yang dilaksanakan oleh pihak lain (Perguruan Tinggi ) bagi guru mata pelajaran matematika SMP/Mts dalam memahami dan menerapkan strategi-strategi dalam memecahkan masalah matematika. Berdasarkan uraian latar belakang di atas maka pihak Universitas Madura (UNIRA) dalam hal ini dosen jurusan pendidikan matematika 
berinisiatif untuk melakukan pelatihan strategi-strategi dalam memecahkan masalah matematika untuk guru smp/mts di kecamatan Pademawu, yang diikuti oleh beberapa sekolah di kecamatan Pademawu baik sekolah negeri maupun sekolah swasta.

\section{Metode Kegiatan}

Metode yang digunakan dalam kegiatan ini adalah pelatihan bagi guruguru SMP/Mts kecamatan Pademawu. Peserta pelatihan yang diundang adalah perwakilan dari 7 sekolah yang terdiri dari 2 SMP Negeri, 1 Mts Negeri dan 4 SMP Swasta. Sekolah-sekolah tersebut dipilih karena selama ini sekolah-sekolah tersebut belum mampu meloloskan siswa-siswanya untuk mewakili kabupaten Pamekasan untuk mengikuti OSN tingkat Provinsi. Masing-masing sekolah diminta untuk mengirimkan 1 orang guru matematika untuk mengikuti pelatihan. Pelatihan dilaksanakan selama 2 hari mulai tanggal 22 Februari sampai 23 Februari 2016. Berikut ini run down acara pelaksanaan pelatihan:

\begin{tabular}{|c|c|c|c|c|}
\hline Hari/g. & Wasty & Acara & Rembicara & Bemandu \\
\hline \multirow{8}{*}{$\begin{array}{l}\text { Senin/22 } \\
\text { Feb } 2016\end{array}$} & $07.00-08.00$ & Ragistrasi Reserta & & Panitia \\
\hline & $08.00-08.30$ & Rembulash & $\begin{array}{l}\text { Daban FKIPUNIRA } \\
\text { \& Ketua Pelaksana }\end{array}$ & \\
\hline & $08.30-09.30$ & PreTes & & Ranitia \\
\hline & $09.30-10.30$ & $\begin{array}{l}\text { Renyampaian materi } \\
\text { strategi menemulkan } \\
\text { pela dan diskusi }\end{array}$ & $\begin{array}{l}\text { Sri Indriati Hasanah } \\
\text { S.Si, LLPd. }\end{array}$ & MC \\
\hline & $10.30-11.30$ & $\begin{array}{l}\text { Renyampaian materi } \\
\text { strategi menemulan } \\
\text { pela dan diskusi }\end{array}$ & $\begin{array}{l}\text { Sri Indriati Hasmah } \\
\text { S.Si, LIPd. }\end{array}$ & $\mathrm{MC}$ \\
\hline & $11.30-12.30$ & ISHOMA & & Ranitia \\
\hline & $12.30-13.30$ & $\begin{array}{l}\text { Ranyampaian materi } \\
\text { strategi takak dan } \\
\text { pariksa dan diskusi } \\
\text { dan diskusi }\end{array}$ & $\begin{array}{l}\text { Sri Indriati Hasanah } \\
\text { S.Si, LIPd. }\end{array}$ & MC \\
\hline & $13.30-14.30$ & $\begin{array}{l}\text { Tanya iawab tarkait } \\
\text { materiyang } \\
\text { disampailan }\end{array}$ & $\begin{array}{l}\text { Sri Indriati Hasanah } \\
\text { S.Si, LLPd. }\end{array}$ & $\mathrm{MC}$ \\
\hline \multirow{8}{*}{$\begin{array}{l}\text { Salasa/23 } \\
\text { Feb 2016 }\end{array}$} & $07.30-08.00$ & Registrasi Resenta & & Ranitia \\
\hline & $08.00-09.00$ & $\begin{array}{l}\text { Renyampaian materi } \\
\text { strategi } \\
\text { menvelesaikan } \\
\text { masalah yang mirin } \\
\text { atau masalah yang } \\
\text { labih mudab dan } \\
\text { diskusi }\end{array}$ & Hasan Basci. DLPC & \\
\hline & $09.00-10.00$ & $\begin{array}{l}\text { Renyampaian materi } \\
\text { strategi penalaras } \\
\text { dan diskusi }\end{array}$ & Hasan Basci.dLC. & Ranitia \\
\hline & $10.00-11.00$ & $\begin{array}{l}\text { Renyampaian materi } \\
\text { strategi } \\
\text { menvederhanal:an } \\
\text { permasalahan dan } \\
\text { diskusi }\end{array}$ & Hasan Basci. XlPC & $\mathrm{MC}$ \\
\hline & $11.00-12.00$ & $\begin{array}{l}\text { Tanya jawab terbait } \\
\text { materi yang } \\
\text { disampaikan }\end{array}$ & Hasan Basci. VLPC & $\mathrm{MC}$ \\
\hline & $12.00-13.00$ & ISHOMA & & Ranitia \\
\hline & $13.00-14.00$ & PesTa5 & & MC \\
\hline & $14.00-14.30$ & Renutur & & $\begin{array}{c}\text { Katua } \\
\text { Pelaksans }\end{array}$ \\
\hline
\end{tabular}

Pre tes dilakukan untuk mengetahui sejauh mana kemampuan awal peserta pelatihan dalam menyelesaikan masalah matematika. Soal-soal yang diberikan pada saat pre tes merupakan soal-soal yang harus diselesaikan dengan menggunakan strategi-strategi dalam memecahkan masalah matematika seperti strategi menemukan pola, strategi menemukan semua kemungkinan secara sistematik, strategi tebak dan periksa, strategi menyelesaikan masalah yang mirip atau masalah yang lebih mudah, strategi penalaran dan strategi menyederhanakan permasalahan. Berikut soal pre tes yang digunakan untuk mengetahui kemampuan awal peserta. 


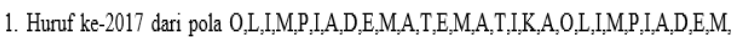
A,T,E,M.A,T,IK, A, ... adalah

2. Misalkan $n$ adalah bilangan asli yang tidak lebih dari 21 , maka jumlah dari semua nilai $n$ yang memenuhi agar $n$ dan 21 relatif prima adalah ....

3. Dengan menggunakan angka-angka 2, 2, 3, 3, 4, 4, 5, 5 bilangan 8 angka terkecil yang dapat dibentuk dengan syarat kedua angka 2 dipisahkan oleh satu angka yang lain, kedua angka 3 dipisahkan oleh dua angka, kedua angka 4 dipisahkan oleh tiga angka, dan kedua angka 5 dipisahkan oleh empat angka adalah...

4. Jika $f(x y)=f(x+y)$ dan $f(8)=8$, maka $f(50)=$

5. Jika luas satu persegi kecil adalah $3 \mathrm{~m}^{2}$, maka luas bangun datar pada gambar di bawah adalah...

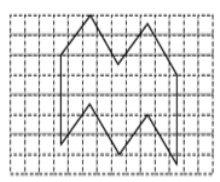

Berikutnya setelah peserta diberikan pre tes, peserta pelatihan diberikan modul yang berisi strategistrategi dalam memecahkan masalah matematika, di hari pertama materi disampaikan oleh Ibu Sri Indriati Hasanah, S.Si, M.Pd yang membahas dan mendiskusikan masalah matematika yang dapat diselesaikan dengan menggunakan strategi menemukan pola, strategi menemukan semua kemungkinan secara sistematik, strategi tebak dan periksa. Berikutnya di hari kedua materi disampaikan oleh Bapak Hasan Basri, M.Pd yang membahas dan mendiskusikan masalah matematika strategi menyelesaikan masalah yang mirip atau masalah yang lebih mudah, strategi penalaran dan strategi menyederhanakan permasalahan.

Setelah pemateri melakukan pemaparan dan berdiskusi terkait materi yang disampaikan selanjutnya, peserta diberikan latihan-latihan soal untuk mengetahui sejauh mana pemahaman peserta terhadap strategi pemecahan masalah matematika. Kemudian di akhir pelatihan peserta diminta untuk mengerjakan pos tes untuk mengetahui hasil akhir yang diperoleh peserta pelatihan selama dua hari mengikuti pelatihan strategi-strategi dalam menyelesaikan masalah matematika. Berikut soal pos tes yang diberikan kepada peserta pelatihan.

\footnotetext{
1. Misalkan $n$ adalah bilangan asli yang tidak lebih dari 24 , maka jumlah dari semua nilai $n$ yang memenuhi agar $n$ dan 24 relatif prima adalah .

2. Huruf ke-2016 dari pola $\mathrm{O}_{2} \mathrm{~L}, \mathrm{I}, \mathrm{M}, \mathrm{P}, \mathrm{I}, \mathrm{A}, \mathrm{D}, \mathrm{E}, \mathrm{S}, \mathrm{A}, \mathrm{I}, \mathrm{N}, \mathrm{S}, \mathrm{O}, \mathrm{L}, \mathrm{I}, \mathrm{M}, \mathrm{P}, \mathrm{I}, \mathrm{A}, \mathrm{D}, \mathrm{E}, \mathrm{S}, \mathrm{A}, \mathrm{I}, \mathrm{N}, \mathrm{S}, \ldots$ adalah

3. Bapak dan ibu Zaenal sedang merencanakan nama bagi anak mereka yang akan segera lahir dengan nama yang terdiri dari 3 kata dengan nama belakang Zaenal. Mereka menginginkan inisial/singkatan nama anak tersebut adalah terurut menurut abjad dengan tak ada huruf yang berulang, sebagai contoh $G T Z$, tetapi mereka tidak mau $T G Z$. Banyak pilihan inisial nama yang dapat dipergunakan adalah ....

4. Dengan menggunakan angka-angka 1, 1, 2, 2, 3, 3, 4, 4 bilangan 8 angka terkecil yang dapat dibentuk dengan syarat kedua angka 1 dipisahkan oleh satu angka yang lain, kedua angka 2 dipisahkan oleh dua angka, kedua angka 3 dipisahkan oleh tiga angka, dan kedua angka 4 dipisahkan oleh empat angka adalah ..
}

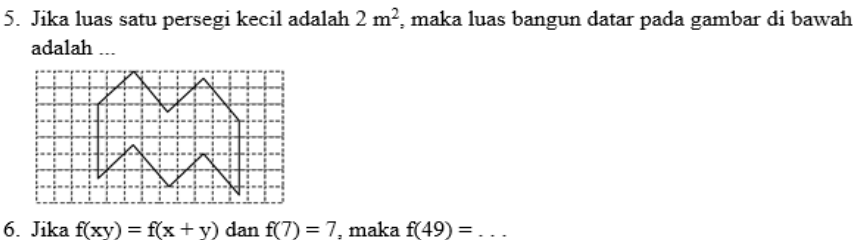

6. Jika $f(x y)=f(x+y)$ dan $f(7)=7$, maka $f(49)=\ldots$

\section{HASIL DAN PEMBAHASAN}

Setelah pemberian pre tes dan pemaparan materi pada hari pertama, dilanjutkan dengan pemaparan materi pada hari kedua dan diakhiri dengan pemberian soal pos tes kepada peserta pelatihan. Dari 7 sekolah yang diundang untuk mendelegasikan 1 orang guru matematika untuk mengikuti pelatihan, hanya 4 sekolah saja yang memenuhi undangan panitia dan terlibat dalam kegiatan pelatihan. Ketidakhadiran beberapa peserta 
dikarenakan adanya kegiatan lain yang bersamaan dengan kegiatan ini.

Berikut disajikan hasil pre test dan post test dari peserta pelatihan:

Tabel 1. Hasil Prestest dan

Postest Peserta

\begin{tabular}{|c|c|c|}
\hline $\begin{array}{l}\text { Inisial Peserta } \\
\text { Pelatihan }\end{array}$ & Pre test & Post test \\
\hline RD & 17 & 50 \\
\hline RDS & 17 & 83 \\
\hline SH & 10 & 67 \\
\hline LA & 8 & 58 \\
\hline
\end{tabular}

Berdasarkan hasil pre tes di atas terlihat bahwa kemampuan awal peserta pelatihan sangat rendah hal ini terlihat dari hasil pre tes peserta pelatihan, dengan nilai tertinggi hanya 17 dengan skala 100. Setelah dua hari memperoleh pengetahuan tentang strategi-strategi dalam memecahkan masalah ada perubahan yang cukup baik hal ini dapat dilihat dari hasil pos tes peserta pelatihan yang mengalami peningkatan. Selain itu berdasarkan pengamatan kami, para peserta nampak antusias dan memiliki rasa percaya diri yang tinggi dalam menyelesaikan soal-soal pemecahan masalah setelah pemateri memaparkan strategi-strategi dalam memecahkan masalah. Panitia juga memberikan modul yang berisi enam strategi pemecahan masalah yaitu : menggunakan strategi menemukan pola, strategi menemukan semua kemungkinan secara sistematik, strategi tebak dan periksa, strategi menyelesaikan masalah yang mirip atau masalah yang lebih mudah, strategi penalaran dan strategi menyederhanakan permasalahan. Dengan demikian diharapkan peserta pelatihan dapat memberikan pelatihan yang sama untuk guru matematika di sekolahnya masing-masing, atau melalui kegiatan MGMP yang rutin mereka laksanakan.

\section{KESIMPULAN DAN SARAN}

Kegiatan ini banyak manfaatnya bagi para peserta pelatihan. Hal ini dibuktikan dengan hal-hal sebagai berikut:

1. Hasil pos tes peserta pelatihan jauh meningkat dibandingkan dengan hasil pre test peserta sebelum mendapatkan materi pelatihan strategi-strategi dalam memecahkan masalah matematika.

2. Para peserta pelatihan yang sangat antusias dalam bertanya dan berdiskusi mengenai materi yang dipaparkan oleh pemateri bahkan menanyakan keberlanjutan dari kegiatan pelatihan ini.

3. Karena keterbatasan waktu dan biaya dalam pelatihan ini hanya membahas 6 strategi dalam memecahkan masalah matematika dan hanya mengundang 7 sekolah, oleh karena itu kegiatan ini perlu dilanjutkan untuk membahas strategi-strategi yang lain dalam memecahkan masalah matematika. 


\section{DAFTAR PUSTAKA}

Depdiknas. 2006. Kurikulum 2006,

Standar Kompetensi Mata

Pelajaran Matematika SMP dan

MTs. Jakarta : Depdiknas

Irawati, S. Hasanah, I.S. 2016.

Representasi Mahasiswa

Berkemampuan Matematika Tinggi

Dalam Memecahkan Masalah

Program Linier. 18 (1). 80-86

Kemdikbud. 2014. Matematika SMP/MTs

Kelas VII Semester 1 edisi revisi

2014. Jakarta : Kemdikbud

Kemdikbud. 2014. Matematika SMP/MTs

Kelas VIII Semester 1 edisi revisi

2014. Jakarta : Kemdikbud

Polya, G. 1973. How To Solve It. New Jersey : Princeton University Press (300)

Suherman, Erman. 2003. Strategi Pembelajaran Matematika

Kontemporer. Jurusan Pendidikan

Matematika FMIPA. Universitas

Pendidikan Indonesia. Bandung. 